Cultivating organizational compassion in healthcare

\author{
Dr Ace Volkmann Simpson \\ ace.simpson@uts.edu.au
}

UTS Business School, Management Discipline Group

University of Technology Sydney (UTS)

Dr Ben Farr-Wharton

benjamin.farr-wharton@uts.edu.au

UTS Business School, Management Discipline Group

University of Technology Sydney (UTS)

\author{
Professor Prasuna Reddy \\ preddy@swin.edu.au
}

Faculty of Science, Engineering \& Technology

Swinburne University of Technology 


\title{
Cultivating organizational compassion in healthcare
}

\begin{abstract}
The compassion of healthcare workers towards patients is widely recognised, but research suggests a dearth of compassion among co-workers. Indeed, workplace bullying and negative employee outcomes are over represented in the healthcare sector (including burnout and substantial staff turnover). In this paper we discuss the cultivation of compassion for healthcare workers, using the lens of positive organizational scholarship (POS). Our concern is not only with the individual level compassion (i.e. between employees), we also consider how compassion can be cultivated systemically across healthcare institutions at the organizational level. More specifically, we present a proposed NEAR Mechanisms Model of Organizational Compassion as a tool for consciously cultivating workplace compassion in healthcare organizations.
\end{abstract}

Keywords: compassion, group processes, bullying, healthcare, healthcare organizations.

\section{INTRODUCTION}

Healthcare organizations are places where doctors, nurses, allied health and administrative personnel work diligently to mitigate the suffering of patients. Yet the act of providing healthcare can be emotionally challenging and physically draining, particularly when resources are scarce and time is stretched. In this context, disharmony can brew between colleagues, and when a co-worker faces suffering the compassionate acts that are afforded to patients are not necessarily extended to fellow employees. Workplace disharmony is a particularly important consideration in the context of healthcare. Research has highlighted instances of bullying and workplace harassment are generally more prominent among healthcare workers, relative to other occupations (European Agency for Health and Safety at Work [EU-OSHA], 2009). This paper seeks to reframe the issue of disharmony in the healthcare workforce, with a particular focus on the power of organizational compassion. 
Positive Organizational Scholarship (POS), as defined by Cameron \& Caza (2004, p. 731), accounts for "that which is positive, flourishing, and life-giving in an organization." Since first heralded in the American Behavioural Scientist dedicated edition (Volume 47, Number 6), organizational compassion has remained a key component of the POS field, yet application of this concept to the context of healthcare remains nascent. In this paper we propose that research findings on organizational compassion conducted over the past 15 years (see overviews by Dutton \& Workman, 2011; Dutton, Workman \& Hardin, 2014; Lilius, Worline, Dutton, Kanov \& Maitlis, 2011; Worline \& Dutton, 2017) can be readily extended to the context of healthcare organizations. We propose a theoretical model not only as a mechanism to enhance the positive and virtuous associations which society holds towards healthcare and healthcare workers but also to resolve and overcome some of the challenges (particularly workplace bullying and disharmony) frequently reported in such contexts.

A definition of compassion derived by asking healthcare providers about their understanding describes compassion as: "a virtuous response that seeks to address the suffering and needs of a person through relational understanding and action" (Sinclair et al., 2018, p. e019701). A limitation of this definition is that it applies to the individual level and was generated within the context of patient care. Our concern is with integrating compassion sociologically, at the systemic organizational level; thereby including co-worker and workplace relationships, and also the relationships formed between employees and their organization (Kanov et al., 2004). Through this frame, the definition of organizational compassion most commonly cited describes a four-part process of individual or collective: (1) Noticing of a colleague's suffering, (2) Empathising with the colleague's distress, (3) Assessing to understand the context and the causes of the colleague's suffering, and (4) Responding with actions that are aimed at alleviating the colleague's suffering (NEAR) (Dutton et al., 2014; Simpson \& Farr- 
Wharton, 2017). These sub-processes and their application to healthcare, in addition to the organizational mechanisms that support them, are explored in greater detail in the paper.

Organizational research has found that mutual efforts in alleviating a co-worker's suffering through compassionate relations confer significant benefits to individuals and organisations. Included herein are: quickening post-trauma healing (Dutton, Frost, Worline, Lilius \& Kanov, 2002; Lilius et al., 2011; Powley \& Cameron, 2006); enhancing of employees' trust, pride and commitment to the organization, and promotion of higher levels of employee commitment, connection and motivation (Dutton, Lilius \& Kanov, 2007; Frost, Dutton, Worline \& Wilson, 2000; Lilius et al., 2008; Simpson, Cunha \& Rego, 2015); boosting organizational performance (Cameron, Bright \& Caza, 2004); and enhanced employee perceptions of leadership effectiveness (Boyatzis, Smith \& Blaize, 2006; Cameron, Mora, Leutscher \& Calarco, 2011; Crossan, Mazutis \& Seijts, 2013; Dutton et al., 2002). In short, the research literature attributes numerous individual and collective benefits to practices of organizational compassion as a response to employee suffering. Most important for this paper, within the healthcare context, compassion has been found to reduce the effects of work-related stress, and also improve sleep quality and subjective health among nurses (Zhang et al., 2018).

One of our starting assumptions is that healthcare workers enter the profession with virtuous intentions to serve and support humanity with compassion (Eley, Eley \& Rogers-Clark, 2010). Further, we assume that systemic institutional factors undermine this virtuous intention (Crawford, Gilbert, Gilbert, Gale \& Harvey, 2013). Scholars have observed that a gradual decline in compassion within healthcare was precipitated by conscious efforts in the 1960s in the US and the UK to transition away from a vocational model towards a professional model (Straughair, 2012a). This transition was accompanied by a concomitant trend towards marketization where: "A market-driven and bureaucratised approach has 
overtaken the values of care" (Bradshaw, 2009, p. 467); this has also been attributed to a general rise in workplace stress that is faced by healthcare workers. Correspondingly, there have been recent calls for a return to an ethic of care to address the negative associations that have come to be associated with modern, market-driven care (Straughair, 2012a).

Facilitating compassion systemically by focusing on healthcare organizational level considerations is one approach that may assist in enhancing an ethic of care, achieved by establishing a more harmonious, supportive and positive workplace for care-givers. From previous research, we know that specific systemic organizational factors can inhibit or enhance organizational compassion (Dutton, Worline, Frost \& Lilius, 2006). Inhibiting factors include productivity pressures promoted through setting stretch goals, high power distances and high levels of control (Hallowell, 1999). Imposed efficiency and productivity pressures lessen the probability of co-workers recognizing each other's suffering on account of limitations on their available time for connecting and being present to learn more about a colleague's concerns and suffering. Bureaucracy and mechanisms of formal control also have dampening effects on organizational compassion as they reduce employee capabilities for self-organizing compassionate responses to co-worker suffering due to limitations on their autonomy and freedom (Dutton et al., 2006). Hierarchy further undermines organizational compassion by imposing distances that reduce individual inclinations for personally identifying with other people's pain, recasting suffering colleagues at lower levels in the organizational hierarchy as 'the other' (van Kleef et al., 2008).

Our concern in this paper is with the four NEAR sub-processes of organizational compassion, as well as the ten mechanisms that research suggests promote compassion within organizations (Dutton et al., 2006). The ten mechanisms are grouped as two subcategories comprising social architecture and compassion competencies. The six components grouped 
under social architecture are: social networks, culture, roles, routines, leadership, and stories told; while the four mechanisms grouped under compassion competencies that moderate compassion responding are: speed, scope, scale and customisation.

Insert table 1

In this article, we explore the promotion of these ten mechanisms within the healthcare context. In the next section, we explore the concept of organizational compassion and its real and unrealised value in healthcare, before illustrating and explaining the model.

\section{Promoting Compassion in the Professional Healthcare Context}

Considering that compassion seems so much about what the healthcare profession entails, it is surprising that research has found a high prevalence of workplace bullying among healthcare workers (Atkinson \& Jones, 2018). As an example from the Australian healthcare context, a survey of 762 registered Australian nurses found that 61 per cent of respondents reported experiencing at least two instances of bullying within the past 12 months (Allen, Holland \& Reynolds, 2015). Bullying is not restricted to nurses. A survey of 747 Australian doctors found that 25 per cent had experienced some form of bullying within the past 12 months (Askew et al., 2012). An excuse for bullying in the healthcare setting is that strict standards must be upheld. There is no place for mistakes when people's lives are at stake. Interestingly, research by Edmondson (1996) has found differences in assumptions within patient-care teams about the social consequences of medication errors that have significant implications for patient care. Some caregiver teams saw speaking up about the mistakes as "natural and necessary" to set things right, while others saw it as "a last resort" (Edmondson, 
1999, p. 352). The key variable informing these behaviours has come to be known as psychological safety, "a shared belief that the team is safe for interpersonal risk taking", or "a team climate characterized by interpersonal trust and mutual respect in which people are comfortable being themselves" (p. 354). In other words, high levels of psychological safety are translated as better patient outcomes. Worline and Dutton (2017) have drawn upon this work on psychological safety as evidence of the importance of workplace compassion leading to enhanced workplace performance.

Governments and health institutions have paid considerable attention over recent years to workforce and culture issues, adopting organizational policies and practices designed to improve overall staff wellbeing (Francis, 2010). Initiatives have included advances to a wide range of Human Resource Management (HRM) policies and practices; a focus on learning and development programs; and grants and scholarships for staff research projects and professional development. Yet, the care and compassion afforded for those staff involved in the provision and administration of health services warrant more attention in keeping with the profession's unique and substantial emotional challenges. Work within this context is challenging. Roles at all levels, from clinicians to administrators, necessitate interactions with care receivers, which can be inspiring and uplifting, but also emotionally stressful, draining and complex - leading to compassion fatigue (Figley, 1995; Sprang, Clark \& Whitt-Woosley, 2007). The provision of quality care requires effective collaboration between teams and team members, which also poses challenges as groups of people with positive but competing purposes negotiate to achieve shared goals. Passionate personalities, power differences and competing values can clash, creating tension and the potential for negative work acts such as workplace bullying and harassment (Brunetto et al., 2016). Workplace suffering of this nature undermines employees' wellbeing, dignity, humanity and motivation, draining organizational potential. 


\section{Organizational Compassion: A Fresh Approach}

Efforts to address health sector conflict, disharmony and bullying, have traditionally been negatively focused; based on reducing harm and managing risk, with limited demonstrated effectiveness (Atkinson \& Jones, 2018; Gillen, Sinclair, Kernohan, Begley \& Luyben, 2017). Approaches are categorised as primary (policies and action plans that seek to reduce the risk of bullying), secondary (reactive strategies such as staff training, surveys and case resolution processes) and tertiary (addressing the damages of bullying with agreements, counselling and therapy) (World Health Organization, 2008). Comprehensive interventions incorporate elements from all three levels. Best practice guidance recommends promoting awareness of the problem amongst employees, so they embrace rather than resist any intervention; promoting bullying as a problem of the work environment (rather than merely of individuals within the environment); developing workplace codes of conduct that guide organizational culture and leadership practices; and providing training on how to manage bullying cases. Yet, the endurance of workplace bullying despite concerted efforts (Eurofound, 2015) suggests the need for considering alternative approaches. Though well-intentioned, antibullying efforts can make employees feel underappreciated, defensive, resentful and place them under even greater strain.

It is possible to look at this issue from another perspective - that of promoting organizational compassion, as per the approach of POS (Cameron, Dutton \& Quinn, 2003; Cameron \& Spreitzer, 2012; M. P. Cunha, Rego, Simpson \& Clegg, 2019). The literature linking organizational compassion as the antithesis of workplace bullying is mostly implicit. Cambridge University Professor Huppert (2017) has observed: "misconceived anti-bullying programs ... have too often focused on the reduction of harm rather than the promotion of kindness" (p. 230). Others have similarly recognised the value of a more positive approach. Lutgen-Sandvik and Tracy (2012) suggest that "Focusing on workplace positivity, 
compassion, resilience, energy, and wellness may help ameliorate workplace bullying and other negative organizational phenomena like stress and burnout" (p. 36). Sheehan (1999) also argues that "the evidence of bullying behaviours needs to be addressed. There is a need for a new, more compassionate, caring, and capable management style” (p. 63). More recently, in an opinion piece in the Sydney Morning Herald newspaper Trevor Danos, chairman of the Northern Sydney Local Health District, and Dr Frank Daly, Oceania medical director for Ernst \& Young and a non-executive director of the Hush Foundation, wrote:

Compassion, kindness and empathy (and respect) are not just relevant to patients and carers but are just as important in dealings between healthcare professionals. Now is the time for the training of healthcare professionals at all levels to include these softer, but no less important skills (Danos \& Daly, 2018).

Building on these views we suggest that in contexts characterised by enhanced organizational compassion there would be reduced incidents of workplace bullying. This suggestion has the explicit support of a recent study which found that experiences of compassion among nurses were negatively associated with experiences of workplace bullying (Zhang et al., 2018). Our approach differs from other calls for compassion in the healthcare sector in that we shift the full burden of responsibility for compassion away from the individual carer to include the organization, arguing that compassion practices are facilitated or inhibited by organizational elements. Our stance is that while the cultivation of compassion at individual level is important, it is insufficient for cultivation of compassionate workplaces (Dutton et al., 2006). We further advocate a broader compassion between caregivers and support staff, rather than one that is primarily patient focused. Attending to the socio-material structures that (de)legitimise organizational compassion values and practices is far more important (Simpson, Cunha \& Clegg, 2015). Taking such an approach is consistent with calls for a 
structuration theory of safety culture (Groves, Meisenbach \& Scott-Cawiezell, 2011), applied to the context of providing for the safety of healthcare workers.

We also recognise that compassion is complex (Simpson, Clegg, Lopez, et al., 2014), and even characterised by ethical conundrums (Gallagher, 2013), with some arguing that compassion can undermine effective healthcare practice (Faust, 2009; Jeffrey, 2016; Silverman, 2004). Issues of concern include sentimentality as well as the well-documented issue of compassion fatigue among care-givers (Figley, 1995, 2002; Sabo, 2006). While these arguments are beyond the scope of this paper, we hold that such concerns can be addressed, for example, by recognising that compassion is paradoxical, laden with tensions between sentimentality and rationality, weakness and strength, or individual feeling and institutional policy (Araújo, Simpson, Marujo \& Miguel, 2019; Simpson \& Berti, 2019). Organizational scholars hold that paradoxical tensions made salient can be synergistically integrated and transcended to achieve even greater power than that achieved by emphasising any one of the paradoxical poles (M. P. e. Cunha, Simpson, Clegg \& Rego, 2018; Smith \& Lewis, 2012). Recommendations for transcendence within the context of organizational compassion include Habermasian coordinated communicative action between different parties (Araújo et al., 2019), as well as the cultivation of compassion in conjunction with additional positive virtues of wisdom and courage (Simpson \& Berti, 2019). The model we assert in this paper which presents compassion as not just empathy (which is emotional and could be viewed as sentimental) but also as assessing (cognitive and rational) as well as responding (which can draw upon courage) is compatible with these recommendations. We next present an overview of the organizational sub-processes and mechanisms with the objective of presenting a model for developing organizational compassion within the healthcare sector.

\section{Four NEAR Sub-processes and Ten Mechanisms}


Noted above, the sub-processes of Noticing, Empathising, Assessing and Responding

(NEAR) to a colleague's suffering form the foundation of compassion present in organizations. Noticing a co-worker's strains and struggles is the initial sub-process from which the others unfold (Kanov et al., 2004). It begins with acknowledging a co-worker's struggles without yet forming an awareness of their suffering. Noticing initiates awareness, either intuitively, through active listening or through information searching (Way \& Tracy, 2012). Empathising, which tends the be the manner in which psychologists define compassion, is enacted through fellow feeling or "suffering with" another person (Lilius et al., 2011). In contrast to the cognitive focus of noticing, empathy is felt within the (metaphorical) 'heart'. Assessing comprises appraisals of the conditions and circumstances causing a co-worker to suffer. In this fact-finding or sensemaking (Weick, 1995) process evaluations are formed regarding the sufferer's level of responsibility for their situation, and is situated primarily in the (metaphorical) 'head'. Important considerations include whether or not the colleague ignored early warnings, their access to personal resources for addressing their circumstances, and the compresence of contributing factors over which they have little or no control (Simpson, Clegg \& Pitsis, 2014). Responding is the enactment of practical ways of mitigating a colleague's suffering, through strategies of either eliminating, alleviating, or at least helping with tolerating the pain (Lilius et al., 2011). Workplace responding generally involves providing emotional, material, or scheduling flexibility support (Dutton et al., 2014; Lilius et al., 2008).

Mechanisms. Dutton et al. (2006) analysed an empirical case of compassion following a fire that affected organizational members revealing six principles of social architecture and four compassion competencies that operate as organizational compassion mechanisms. Worline and Dutton (2017) have further expanded upon these ten mechanisms in a recent publication. To date, no attempt has been made to systematically link these mechanisms with the four 
NEAR sub-processes that define organizational compassion. In this paper, we integrate the organisational mechanisms and NEAR sub-process proposing the NEAR Mechanisms Model of Organizational Compassion, a practical heuristic device for guiding compassion organizing in healthcare (See figure 1). We suggest that the six aspects of social architecture are most relevant to the sub-processes of Noticing, Empathising and Assessing (NEA), while we view the four competencies as most relevant to the Responding sub-process. We discuss each of the ten mechanisms individually, contextualising them to specific NEAR subprocesses, paying attention to the broader objective of increasing organizational compassion in healthcare settings.

Insert figure 1

\section{'NEA' sub-processes are supported by six mechanisms of social architecture}

Social architecture underlying organizational compassion is an amalgam of six mechanisms: social networks, roles, routines, culture, leadership, and stories told (Dutton et al., 2006; Worline \& Dutton, 2017). While Dutton et al. (2006) have implicitly acknowledged that social architecture supports the $\mathrm{N}$ and $\mathrm{E}$ sub-processes, we make this connection more explicit and further suggest that it also supports A. Accordingly we view the six mechanisms of social architecture, combined with human endeavour, as critical in enabling the NEA subprocesses of compassion organizing. We discuss each of the social architecture mechanisms in turn.

Social networks. Social networks comprise clusters of people who connect on account of common interests, values and identity (Kilduff \& Tsai, 2003). The importance of social networks for quality healthcare is recognised in the literature (Christakis, 2004; Freshman \& 
Rubino, 2004; Meltzer et al., 2010). Organizations with high compassion are characterised by many clusters of people who share high-quality connections and know one another well (Dutton et al., 2006). Signs of suffering such as being unusually distracted, delayed, shorttempered, or hiding injuries are most likely to be picked up by colleagues within a social network. They can then reach out to offer personal presence or communicate with others in the social network to mobilise other personal or institutional resources. The following quote from a member of a US healthcare organization is illustrative of how social networks can mobilise compassionate support for suffering colleagues:

If there's somebody having a hard time with their house, or their family, or financially or anything, word just spreads and we all just pull together and help each other out (Lilius et al., 2011, p. 874).

Healthcare organizations can facilitate the development of social support networks by providing communal spaces that facilitate group interaction, organizing communal events and gatherings such as townhall meetings, bringing members together in work-teams or committees, and by providing resources for work-related interest groups and clubs (Cornwell \& Goodrich, 2009). Social media platforms can also facilitate the coordination of social networks for enhanced connectivity between healthcare providers (Kamel Boulos \& Wheeler, 2007).

Culture. Organizational culture is the sum of the members' shared patterns of meaning, assumptions, behaviours and practices. Schein (1984) observed three levels of organizational culture: level one comprises visible artefacts such as corporate branding, logos, colours, buildings, uniforms, brochures; level two comprises espoused values found in mission statements, value statements and codes of conduct; level three comprises subconscious assumptions, beliefs and values. Despite the rhetoric of mission and value statements promoting humanistic values (i.e. level two), bullying remains widespread even in healthcare 
settings, suggesting that level three, representing members' hidden subconscious values, assumptions and beliefs (Worline \& Dutton, 2017) may be the most relevant for organizational compassion. Low compassion organizations tend to assume that people are expendable human resources and accordingly treat them as such. Espoused values are nonetheless important, particularly when they are underpinned by compatible beliefs and assumptions. In 2010, the UK Department of Health published a National Health Service (NHS) Constitution, with the objective of establishing the values and principles that underpin the public health service. The constitution was accompanied by a number of pledges, one specifically relevant to compassion, including towards co-workers as an integral aspect of nursing care:

Compassion...we respond with humanity and kindness to each person's pain, distress, anxiety or need. We search for the things we can do, however small, to give comfort and relieve suffering. We find time for those we serve and work alongside. We do not wait to be asked, because we care (Department of Health, 2010, p. 10).

Compassionate organizations put a high emphasis on articulating and promoting values that prioritise the human wellbeing, respect and dignity of both their healthcare workers and their patients, above considerations of efficiency and profitability.

Roles. Organizational roles are patterns of behaviour associated with and expected of specific positions (Katz \& Kahn, 1978). Roles identify a person with a recognisable organizational position. Internalised role expectations, reinforced through social interactions, inform personal behaviour. Leading organization compassion scholars Worline and Dutton (2017) highlight distinctions between approaches of role taking and role making. In role taking, a person learns a new role; there is recognition of the difference between the role and the person assuming the role (Iannotti, 1978). In compassionate healthcare organizations each person has the mandate to recognise, reach out and take time to support another co-worker in 
distress. Additionally, there are designated supervisors and counsellors that workers can turn to for support. Role making comprises people creating or innovating new aspects within their existing role. Role makers change learned role expectations. In high compassion healthcare organizations, workers are given autonomy to see caring for each other as part of their role regardless of their job title. This contrasts with low compassion healthcare organizations, where workers tend to view caring for co-workers as the job of a designated supervisor, or caregiver.

Routines. Organizational routines are repetitive interdependent behavioural patterns members adopt in accomplishing their work tasks (Feldman \& Pentland, 2003). While compassion is an individual trait, it can also be systematised and integrated into all aspects of organizational policies and routines. Routine practices of hiring, training, development, performance reviewing and rewarding can also be designed to incorporate values of caring and compassion. Hiring selection processes should include an assessment of individual compassion capabilities using multiple data sources including quantitative measures and qualitative semi-structured interviews (Straughair, 2012b). Teaching and training programs should include modules for developing compassion capabilities (Firth-Cozens \& Cornwell, 2009). Promotion and reward schemes should publicly recognise and reward healthcare staff who demonstrate exemplary compassionate behaviours towards colleagues. Conversely, workplace incivility must be managed with warnings and independent investigation procedures that have real consequences for individuals and organizations. Performance review and evaluation processes should also explicitly reference expectations of compassion towards colleagues.

Leadership. Leadership comprises planning, coordinating, motivating and inspiring members towards achieving organizational objectives (Dover \& Dierk, 2010). Leaders often occupy positions that afford them control and authority over considerable organizational resources. 
Members particularly look to leaders as role models of behaviours expected within the organization. Accordingly, scholars have advocated for the importance of leaders being role models of compassionate care (Dutton et al., 2002). We hold that high compassion healthcare organizations are led by people who regularly highlight the importance of care and compassion for healthcare workers, both within their words and in their deeds. Leaders in healthcare organizations must be seen to model compassionate behaviours in recognising signs of suffering, showing empathy, making sense of people's struggles and responding to address the distress (Firth-Cozens \& Cornwell, 2009). This does not mean that leaders should not be strict in ensuring that standards are upheld, which are of course important in a healthcare context where decisions have life and death consequences. It means they should be sensitive in helping health workers deal with the stresses and struggles of their personal and professional lives.

Stories told. Stories told in organizations convey values and knowledge, infer systems of meaning, as well as build trust and inspiration and motivation (Czarniawska \& Joerges, 1997). Organizations are, after all, social constructions that depend on symbols, histories and assumptions for maintaining and stabilising culture. Stories communicate understanding about a specific organization and its members, thereby informing individual members about their role expectations as an employee of a particular institution. In high compassion healthcare organizations members can easily recount stories of managers or other colleagues making special efforts to provide support to another member in a suffering condition. For example, the following two stories appear in a publication by Lilius et al. (2008) about a highly compassionate unit in a healthcare organization. The first is told by a recipient of compassion from her colleagues:

One Friday late afternoon I was swamped with phone calls to patients and finishing paper work that had to be completed. It was $5: 45 \mathrm{pm}$, and I felt close to tears, but tried 
to hide it. Two co-workers took their coats off and spent 10-15 minutes helping me finish. Their act of compassion was most appreciated. I can't remember feeling like this before or after that day at work. I love my job! (p. 205).

A second story concerns a group effort to provide compassionate support to a co-worker:

A co-worker's mom and dad both had cancer. She needed to take leave to care for her parents. Our department donated vacation hours and personal hours and was able to present her with a check for over $\$ 1000.00$. We also donated meals that we delivered to her, and spent time sitting for her so she could run errands or rest. My friend is back to work, but as her mom's cancer progresses I'm sure she'll need to take off again and we'll all be there to help. What comes around goes around. We have to be here for each other (p. 204).

In high compassion healthcare organizations such stories will be widely known amongst the staff. Conversely, in low compassion healthcare organizations, such stories are difficult to recall. To the contrary, when asking for exemplar stories of compassion from the organization, workers will instead volunteer stories of bullying and harassment. Healthcare organizations can also publish stories of compassion in internal staff newsletters.

\section{' $R$ ' sub-process is supported by four organizational compassion competencies}

Up until this point we have presented the mechanisms most relevant to the NEA subprocesses while recognising they also overlap with the response sub-process. Unless and until a response is undertaken, the process is incomplete as organizational compassion. While psychology tends to perceive compassion as essentially an internal feeling, organizationally compassion is viewed as a practical enactment seeking to alleviate a colleague's suffering. The accomplishment of a response is what sets compassion apart from empathy (Dutton et al., 2002). The variance among four response mechanisms indicates whether the competency 
of an organizational compassion response is high or low: speed, scope, scale and customisation (Dutton et al., 2002; Dutton et al., 2006). We discuss each of these in turn. Speed. Speed in providing support concerns the amount of time that passes between the points where a colleague's suffering has been noticed and responses are deployed for alleviating their suffering (Dutton et al., 2002; Dutton et al., 2006). More time taken to respond indicates less speed in compassion organizing; conversely, the less time taken to respond, indicates a faster speed of the compassion organizing. Healthcare work environments where patients' lives are at stake can be highly stressful and straining on workplace relationships; compassionate healthcare organizations are therefore quick to recognise and attend to signs of their care provider's suffering. While healthcare organizations might have a zero tolerance policy regarding workplace bullying, the process of determining what constitutes harassment and bullying can become overly legalistic and delayed, giving rise to an experience of "status limbo" (Dzurec, 2013, p. e1). Delays in responding to employee concerns can come across as the workplace protecting the organization rather than for supporting the employee, where the overall effect can be a sense that the organization does not really care about the individual (Simpson, Cunha \& Clegg, 2015; Simpson, Cunha \& Rego, 2015). In organizations that prioritise noticing and compassionately responding to employee suffering such delays are less likely to occur. Due to the culture of compassion, employees at all levels are aware of the legitimacy of taking extraordinary measures to respond to a co-worker or subordinate's suffering, with ongoing permission to suspend usual routines to address the concerns of a suffering colleague. The other competencies and principles discussed below can help with speeding up the noticing and responding to employee suffering.

Scope. The scope of support provided by compassionate organizations is a consideration of the variety of resources available for alleviating the suffering of colleagues (Dutton et al., 
2006). A greater variety of resources available for providing support to alleviate a colleague's suffering, the greater the scope of organized compassion. High compassion healthcare organizations are able to access a vast array of resources to address an employee's suffering (Straughair, 2012b). Available resources can include the providing of counselling and psychological support to address emotional or psychological distress, including that caused by workplace bullying. They may also take the form of arranging legal advice to help with criminal, relational or other workplace safety issues, once again, including workplace bullying. For healthcare workers facing financial hardship, support might take the form of paying their wages a few weeks in advance to address a pressing financial concern. For those with family challenges such as a sick child or spouse support might take the form of providing flexible work hours, or opportunities to work from home. The following quote is illustrative of how colleagues and a department supported a nurse and a mother undergoing cancer treatment:

A co-worker was diagnosed with breast cancer. We all decided how to best handle the absences of the co-worker who was a single mother, so it was important to help her at home during her chemo. Our department set up a rotating schedule to bring the family dinner each night for a six-week period, and to cover her work activities as well (Lilius et al., 2008, p. 206).

Illness or bereavement are cases where the provided support might take the form of a period of extended paid leave. These forms of support are largely dependent upon being integrated within the healthcare organization's workplace policy.

At a personal level, there are relational resources of time and presence that colleagues and supervisors can offer in support (Lilius et al., 2011). It can take the form of just noticing signs of suffering in a colleague's disposition or behaviour, enquiring after their welfare and being present for them to talk about their experiences. Or it may involve sending "get well" cards to 
those who are ill, or making a collection for those who have been robbed. In situations of illness or injury temporarily incapacitating a healthcare worker, colleagues may help by taking turns in providing child-minding support or in cooking meals.

Scale. The scale of support provided in compassionate organizations concerns the quantity of resources provided for alleviating the suffering of colleagues (Dutton et al., 2006).

Compassionate healthcare organizations are able to address employee suffering on an ongoing basis across many instances because they allocate resources for employee care (Straughair, 2012b). More than paying mere lip service to an employee's distress, these organizations invest significant physical and emotional resources into addressing healthcare worker suffering. In contrast, low compassion organizations might provide compassionate support as a rare episode rather than as a general mode of practice.

Customization. Customising of support in compassionate organizations contributes towards ensuring that the provided support matches the specific needs of the colleague who suffers (Dutton et al., 2006). Differences in personality, circumstances and modes of distress suggest the need for varied response types. High compassion healthcare organizations are therefore able to customize their care according to the unique situation and needs of the employee who is suffering (Lilius et al., 2011). Some workers will respond best to the institutional forms of support whereas for others it will be the personal support that will make the biggest difference. Understanding the type of support that would best address the needs of the individual healthcare worker involves actually asking them about the type of support that would best help their situation and making an effort to see how that can be provided within institutional policy frameworks. Importantly, even after support has been offered, ongoing efforts should be made to check on how the recipient's situation has evolved (Simpson, Clegg \& Cunha, 2013). Depending on how the situation has unfolded it may also require adjusting the arrangements of support to meet the individual's changing needs. 


\section{Discussion and Conclusion}

In this paper we have argued that promoting compassion for co-workers as well as patients within healthcare, is a positive way for addressing the persistent problem of workplace bullying in the sector (Huppert, 2017; Zhang et al., 2018). We are not suggesting that organizations dismiss traditional approaches to managing workplace suffering such as adhering to standards of occupational health and safety, implementing bullying and harassment policies, or providing conflict resolution ombudsmen processes. Instead, we are proposing that the important role played by compassion in healthcare organizations should be

additionally recognised and systematised. We assert this approach as an important application of POS applied to the provision of healthcare and associate it with a positive endeavour to rehumanise care organizations. We have accordingly presented the NEAR Mechanisms Model of Organizational Compassion by integrating organizational compassion sub-processes and mechanisms to support the conscious cultivation of compassion in healthcare organizations. While the suggestions posited in the article are steeped in tangible, operational action for healthcare organizations, broader questions remain concerning which parties would be responsible for embedding compassion within their organization's structures. We offer a few suggestions. From a governance perspective, each of the many different layers of staffing types present in healthcare organizational hierarchies have a role to play in embedding compassion. In the first instance, organizational compassion is of a key concern for the workforce stewards within healthcare organizations, including human resource management divisions, wellbeing teams, as well as executives and divisional managers. These parties play key roles in framing the employee experience, and thus can shape, instil and promote compassion through targeted staff recruitment, skills training, educational campaigns, performance reviews, and promotions etc. From a business performance perspective, these stakeholders will likely see the macro benefits generated through compassion, for example in 
a reduction of workplace bullying and compensation claims, better patient care, higher levels of morale, greater resilience, and potentially also lower levels of sick leave (as staff support each other, at work, through trying experiences).

Healthcare organizational line managers; directors of nursing, chief surgeons, senior allied health professionals etc. also bear responsibility in informally cultivating and role modelling compassion across the teams they manage. Notwithstanding this, employees themselves are the most salient stakeholder in the wholesale adoption of organizational compassion. Compassion, inevitably, is a choice for which employees have agency in deciding when to, how to, and to what extent they notice, assess, empathize with and respond to suffering. While those frontline healthcare employees who have experienced compassion from colleagues may in turn feel encouraged to reciprocate this behaviour when confronted by the suffering of others; instilling compassion across the frontline employees of healthcare organizations will require acts of altruism. As postulated above, while programs that cultivate organizational compassion may be encouraged from hierarchies present within healthcare settings, individual and personal transformation may be required for staff to overcome cultural norms and normative forces concerning the application of compassion to address the suffering of colleagues (which is, as argued in this paper, different from that of patients). We accordingly invite healthcare leaders at all levels to take the NEAR Mechanisms Model as a draught framework by adopting and adapting this model to the contexts of their respective organizations.

The arguments we have offered in this paper can be summarised as two groups of recommendations for designing compassion within healthcare organizations. First, support the NEA sub-processes by creating the social architecture of the healthcare organization. Identify natural social networks and find ways for the organization to foster and strengthen them through the promotion community events, interest groups and societies. Ensure the 
organization's espoused values underscore principles supportive of a culture of care and compassion. Incorporate compassion practices into new role descriptions and support holders of existing positions in reflecting on re-making their roles by integrating more care and compassion. Update recruitment, induction, evaluation and reward routines, to emphasise fit with a culture of compassion. Select and promote leaders on the basis of the candidate's demonstrated compassion competencies. Broadcast stories of episodes where members have risen above workplace expectations in responding to the suffering of other colleagues.

Second, measure your social architecture's performance in promoting compassion R against the following compassion capabilities criteria: What is the speed of your organization's responses to employee suffering? Does the scope of your organization's support accommodate a wide variety of personalities and circumstances? Is the scale of the resources your organization invests in providing support sufficient? Is the support offered to employees in distress customisable to address specific needs?

Finally, while the ideas put forth in this paper make intuitive sense, investigations of organizational compassion in healthcare settings are still in their infancy and have yet to be studied quantitatively in any depth, using validated measures of the constructs. For the most part, the existing body of literature on organizational compassion is qualitative in nature (Huppert, 2017). An important next step for organizational compassion research is testing current findings using quantitative methodologies and valid and reliable measures. This process is already underway with the NEAR Organizational Compassion Scale, which demonstrates strong validity and reliability (Simpson \& Farr-Wharton, 2017). A scale of this sort ought to be used along with validated scales of organizational bullying to evaluate the effectiveness of interventions aimed at enhancing compassion capabilities in healthcare organizations. 


\section{References}

Allen, B. C., Holland, P., \& Reynolds, R. (2015). The effect of bullying on burnout in nurses: the moderating role of psychological detachment. Journal of advanced nursing, 71(2), 381-390.

Araújo, M. L., Simpson, A. V., Marujo, H. A., \& Miguel, L. P. (2019). Selfless and strategic, interpersonal and institutional: A continuum of paradoxical organizational compassion dimensions. Journal of Political Power, Under review.

Askew, D. A., Schluter, P. J., Dick, M.-L., Régo, P. M., Turner, C., \& Wilkinson, D. (2012). Bullying in the Australian medical workforce: cross-sectional data from an Australian e-Cohort study. Australian health review, 36(2), 197-204.

Atkinson, V., \& Jones, C. (2018). Endemic unprofessional behaviour in health care: the mandate for a change in approach. Medical Journal of Australia, 209(9), 380-381.

Boyatzis, R. E., Smith, M. L., \& Blaize, N. (2006). Developing sustainable leaders through coaching and compassion. The Academy of Management Learning and Education, 5(1), 8-24.

Bradshaw, A. (2009). Measuring nursing care and compassion: the McDonaldised nurse? Journal of Medical Ethics, 35(8), 465-468.

Brunetto, Y., Xerri, M., Trinchero, E., Farr-Wharton, R., Shacklock, K., \& Borgonovi, E. (2016). Public-Private Sector Comparisons of Nurses’ Work Harassment Using Set: Italy and Australia. Public Management Review, 18(10), 1479-1503.

Cameron, K. S., Bright, D., \& Caza, A. (2004). Exploring the relationships between organizational virtuousness and performance. American Behavioral Scientist, 47(6), 766-790.

Cameron, K. S., Dutton, J. E., \& Quinn, R. E. (2003). Foundations of Positive Organizational Scholarship. In K. S. Cameron, J. E. Dutton, \& R. E. Quinn (Eds.), Positive organizational scholarship: Foundations of a new discipline (pp. 3-13). San Francisco Berrett-Koehler Publishers.

Cameron, K. S., Mora, C., Leutscher, T., \& Calarco, M. (2011). Effects of positive practices on organizational effectiveness. The journal of applied behavioral science, 47(3), 266-308.

Cameron, K. S., \& Spreitzer, G. M. (2012). The Oxford handbook of positive organizational scholarship. Oxford: Oxford University Press.

Christakis, N. A. (2004). Social networks and collateral health effects. British Medical Journal, 329, 184-185.

Cornwell, J., \& Goodrich, J. (2009). Exploring how to ensure compassionate care in hospital to improve patient experience. Nursing Times, 105(15), 14-16.

Crawford, P., Gilbert, P., Gilbert, J., Gale, C., \& Harvey, K. (2013). The language of compassion in acute mental health care. Qualitative Health Research, 23(6), 719-727.

Crossan, M., Mazutis, D., \& Seijts, G. (2013). In search of virtue: The role of virtues, values and character strengths in ethical decision making. Journal of Business Ethics, 113(4), 567-581.

Cunha, M. P., Rego, A., Simpson, A. V., \& Clegg, S. (2019). Positive organizational behaviour: Management as a force for good: Routledge.

Cunha, M. P. e., Simpson, A. V., Clegg, S. R., \& Rego, A. (2018). Speak! Paradoxical Effects of a Managerial Culture of 'Speaking Up'. British Journal of Management.

Czarniawska, B., \& Joerges, B. C. (1997). Narrating the organization: Dramas of institutional identity: University of Chicago Press.

Danos, T., \& Daly, F. (2018, 6 June). More compassion and empathy will improve our health system. Sydney Morning Herald $\mathrm{p}$. Online. Retrieved from https://www.smh.com.au/national/nsw/more-compassion-and-empathy-will-improve-ourhealth-system-20180606-p4zity.html

Department of Health. (2010). The NHS Constitution. London: The Stationary Office.

Dover, P. A., \& Dierk, U. (2010). The ambidextrous organization: integrating managers, entrepreneurs and leaders. Journal of Business Strategy, 31(5), 49-58.

Dutton, J. E., Frost, P., Worline, M. C., Lilius, J. M., \& Kanov, J. M. (2002). Leading in times of trauma. Harvard business review, 80(1), 54-61. 
Dutton, J. E., Lilius, J. M., \& Kanov, J. M. (2007). The transformative potential of compassion at work. In S. K. Piderit, R. E. Fry, \& D. L. Cooperrider (Eds.), Handbook of transformative cooperation: New designs and dynamics (pp. 107-124). Stanford: Stanford University Press.

Dutton, J. E., \& Workman, K. M. (2011). Compassion as a generative force. Journal of Management Inquiry, 20(4), 402-406.

Dutton, J. E., Workman, K. M., \& Hardin, A. E. (2014). Compassion at work. Annual Review of Organizational Psychology and Organizational Behavior, 1, 277-304.

Dutton, J. E., Worline, M. C., Frost, P. J., \& Lilius, J. (2006). Explaining compassion organizing. Administrative science quarterly, 51(1), 59-96.

Dzurec, L. C. (2013). Status limbo: Analysis of nurse faculty member reports of administrator response to workplace bullying complaints. Journal of Professional Nursing, 29(5), e1-e9.

Edmondson, A. C. (1996). Learning from mistakes is easier said than done: Group and organizational influences on the detection and correction of human error. The journal of applied behavioral science, 32(1), 5-28.

Edmondson, A. C. (1999). Psychological safety and learning behavior in work teams. Administrative science quarterly, 44(2), 350-383.

Eley, R., Eley, D., \& Rogers-Clark, C. (2010). Reasons for entering and leaving nursing: an Australian regional study. Australian Journal of Advanced Nursing, 28(1), 6-12.

Eurofound. (2015). First findings: Sixth European Working Conditions Survey. https://www.eurofound.europa.eu/sites/default/files/ef_publication/field_ef_document/ef1568 en.pdf

European Agency for Health and Safety at Work [EU-OSHA]. (2009). Workplace violence and harassment: a European picture. European Risk Observatory Report.

Faust, H. S. (2009). Kindness, not compassion, in healthcare. Cambridge Quarterly of Healthcare Ethics, 18(3), 287-299.

Feldman, M. S., \& Pentland, B. T. (2003). Reconceptualizing organizational routines as a source of flexibility and change. Administrative science quarterly, 48(1), 94-118.

Figley, C. R. (1995). Compassion fatigue: Coping with secondary traumatic stress disorder in those who treat the traumatized. London: Brunner-Routledge.

Figley, C. R. (2002). Compassion fatigue: psychotherapists' chronic lack of self care. Journal of Clinical Psychology, 58(11), 1433-1441.

Firth-Cozens, J., \& Cornwell, J. (2009). The point of care: Enabling compassionate care in acute hospital settings. London: The Kings Fund.

Francis, R. (2010). Independent inquiry into care provided by mid Staffordshire NHS Foundation Trust January 2005-March 2009 (Vol. 1 and 2): The Stationery Office.

Freshman, B., \& Rubino, L. (2004). Emotional intelligence skills for maintaining social networks in healthcare organizations. Hospital Topics, 82(3), 2-9.

Frost, P. J., Dutton, J. E., Worline, M. C., \& Wilson, A. (2000). Narratives of compassion in organizations. In S. Fineman (Ed.), Emotions in organizations (pp. 25-45). London: Sage.

Gallagher, A. (2013). Compassion conundrums: Sage Publications Sage UK: London, England.

Gillen, P. A., Sinclair, M., Kernohan, W. G., Begley, C. M., \& Luyben, A. G. (2017). Interventions for prevention of bullying in the workplace. Cochrane Database of Systematic Reviews, CD009778(1), 1-67.

Groves, P. S., Meisenbach, R. J., \& Scott - Cawiezell, J. (2011). Keeping patients safe in healthcare organizations: a structuration theory of safety culture. Journal of advanced nursing, 67(8), 1846-1855.

Hallowell, E. M. (1999). The human moment at work. Harvard business review(January-February), 18.

Huppert, F. A. (2017). Mindfulness and compassion as foundations for well-being. In M. A. White, G. R. Slemp, \& A. S. Murray (Eds.), Future Directions in Well-Being: Education, Organizations and Policy (pp. 225-233): Springer.

Iannotti, R. J. (1978). Effect of role-taking experiences on role taking, empathy, altruism, and aggression. Developmental Psychology, 14(2), 119-124.

Jeffrey, D. (2016). Empathy, sympathy and compassion in healthcare: Is there a problem? Is there a difference? Does it matter? Journal of the Royal Society of Medicine, 109(12), 446-452. 
Kamel Boulos, M. N., \& Wheeler, S. (2007). The emerging Web 2.0 social software: an enabling suite of sociable technologies in health and health care education 1. Health Information \& Libraries Journal, 24(1), 2-23.

Kanov, J. M., Maitlis, S., Worline, M. C., Dutton, J. E., Frost, P. J., \& Lilius, J. M. (2004). Compassion in organizational life. American Behavioral Scientist, 47(6), 808-827.

Katz, D., \& Kahn, R. L. (1978). The social psychology of organizations (Vol. 2): Wiley New York.

Kilduff, M., \& Tsai, W. (2003). Social networks and organizations. London: Sage.

Lilius, J. M., Worline, M. C., Dutton, J. E., Kanov, J. M., \& Maitlis, S. (2011). Understanding compassion capability. Human relations, 64(7), 873-899.

Lilius, J. M., Worline, M. C., Maitlis, S., Kanov, J. M., Dutton, J. E., \& Frost, P. J. (2008). The contours and consequences of compassion at work. Journal of Organizational Behavior, 29(2), 193-218.

Lutgen-Sandvik, P., \& Tracy, S. J. (2012). Answering five key questions about workplace bullying: How communication scholarship provides thought leadership for transforming abuse at work. Management Communication Quarterly, 26(1), 3-47.

Meltzer, D., Chung, J., Khalili, P., Marlow, E., Arora, V., Schumock, G., \& Burt, R. (2010). Exploring the use of social network methods in designing healthcare quality improvement teams. Social science \& medicine, 71(6), 1119-1130.

Powley, E. H., \& Cameron, K. S. (2006). Organizational healing: Lived virtuousness amidst organizational crisis. Journal of Management, Spirituality \& Religion, 3(1-2), 13-33.

Sabo, B. M. (2006). Compassion fatigue and nursing work: can we accurately capture the consequences of caring work? International journal of nursing practice, 12(3), 136-142.

Schein, E. H. (1984). Coming to a new awareness of organizational culture. Sloan Management Review, 25(2), 3-16.

Sheehan, M. (1999). Workplace bullying: Responding with some emotional intelligence. International journal of manpower, 20(1/2), 57-69.

Silverman, W. A. (2004). Compassion or opportunism? Pediatrics, 113(2), 402-403.

Simpson, A. V., \& Berti, M. (2019). Transcending organizational compassion paradoxes by enacting wise compassion courageously. Journal of Management Inquiry, Published online ahead of print.

Simpson, A. V., Clegg, S., \& Cunha, M. P. (2013). Expressing compassion in the face of crisis: Organizational practices in the aftermath of the Brisbane floods of 2011. Journal of Contingencies and Crisis Management, 21(2), 115-124.

Simpson, A. V., Clegg, S., Lopez, M. P., Cunha, M. P., Rego, A., \& Pitsis, T. (2014). Doing compassion or doing discipline? Power relations and the Magdalene Laundries. Journal of Political Power, 7(2), 253-274.

Simpson, A. V., Clegg, S., \& Pitsis, T. (2014). Normal compassion: A framework for compassionate decision making. Journal of Business Ethics, 119(4), 473-491.

Simpson, A. V., Cunha, M. P., \& Clegg, S. (2015). Hybridity, sociomateriality and compassion: What happens when a river floods and a city's organizations respond? Scandinavian Journal of Management, 31(3), 375-386.

Simpson, A. V., Cunha, M. P., \& Rego, A. (2015). Compassion in the context of capitalistic organizations: Evidence from the 2011 Brisbane floods. Journal of Business Ethics, 130(3), 683-703.

Simpson, A. V., \& Farr-Wharton, B. (2017). NEAR Organizational Compassion Scale: validity, reliability and correlations. Paper presented at the Australian and New Zealand Academy of Management (ANZAM), RMIT, Melbourne Australia.

Sinclair, S., Hack, T. F., Raffin-Bouchal, S., McClement, S., Stajduhar, K., Singh, P., . . Chochinov, H. M. (2018). What are healthcare providers' understandings and experiences of compassion? The healthcare compassion model: a grounded theory study of healthcare providers in Canada. BMJ open, 8(3), e019701.

Smith, W. K., \& Lewis, M. W. (2012). Leadership skills for managing paradoxes. Industrial and Organizational Psychology, 5(2), 227-231. 
Sprang, G., Clark, J. J., \& Whitt-Woosley, A. (2007). Compassion fatigue, compassion satisfaction, and burnout: Factors impacting a professional's quality of life. Journal of Loss and Trauma, 12(3), 259-280.

Straughair, C. (2012a). Exploring compassion: implications for contemporary nursing. Part 1. British Journal of Nursing, 21(3), 160-164.

Straughair, C. (2012b). Exploring compassion: implications for contemporary nursing. Part 2. British Journal of Nursing, 21(4), 239-244.

van Kleef, G. A., Oveis, C., Van der Lowe, I., LuoKogan, A., Goetz, J., \& Keltner, D. (2008). Power, distress, and compassion. Psychological Science, 19(12), 1315-1322.

Way, D., \& Tracy, S. J. (2012). Conceptualizing compassion as recognizing, relating and (re) acting: A qualitative study of compassionate communication at hospice. Communication monographs, 79(3), 292-315.

Weick, K. E. (1995). Sensemaking in organizations. Thousand Oaks, CA: Sage Publications.

World Health Organization. (2008). Best practice in Workplace Violence and Bullying Interventions Occupational Health and Safety Publications, 10.

Worline, M., \& Dutton, J. E. (2017). Awakening compassion at work: The quiet power that elevates people and organizations. Oakland, CA: Berrett-Koehler Publishers.

Zhang, S.-E., Liu, W., Wang, J., Shi, Y., Xie, F., Cang, S., . . Fan, L. (2018). Impact of workplace violence and compassionate behaviour in hospitals on stress, sleep quality and subjective health status among Chinese nurses: a cross-sectional survey. BMJ open, 8(10), e019373. 
Table 1: Organizational compassion NEAR subprocess and ten mechanisms.

\begin{tabular}{|l|l|l|}
\hline \multirow{2}{*}{$\begin{array}{c}\text { Organizational } \\
\text { Compassion NEAR Sub- } \\
\text { Processes }\end{array}$} & \multicolumn{2}{c|}{ Ten Supportive Mechanisms } \\
\cline { 2 - 3 } Noticing & Social Networks & Speed \\
\hline Empathising & Culture & Scope \\
\hline Assessing & Roles & Scale \\
\hline Responding & Routines & Customisation \\
\cline { 2 - 2 } & Leadership & \\
\cline { 2 - 2 } & Stories Told & \\
\hline
\end{tabular}

Figure 1: The NEAR Mechanisms Model of Organizational Compassion: An integrated model of four organizational compassion NEAR sub-processes and ten mechanisms.

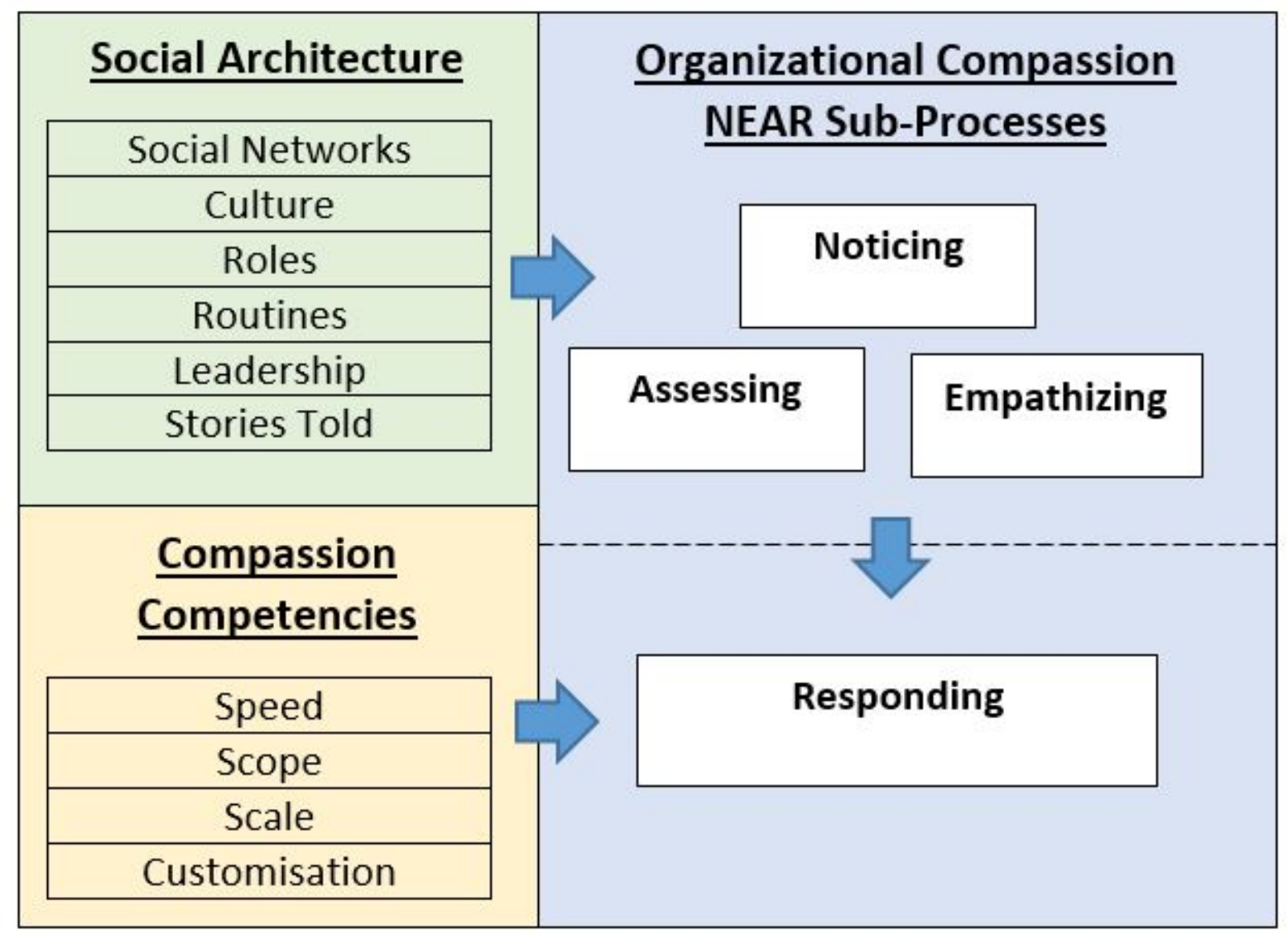

